\title{
DESIGN AND IMPLEMENTATION OF AN SMS-BASED ROBOTIC SYSTEM FOR HOLE- DETECTION IN SURFACE PIPES USING GPS/GPRS/GSM TECHNOLOGY
}

\author{
Ezeofor J. Chukwunazo ${ }^{1}$, Georgewill M. Onengiye ${ }^{2}$ \\ ${ }^{1}$ Lecturer, Electronic \& Computer Engineering, University of Port Harcourt, Rivers State, Nigeria \\ ${ }^{2}$ Rector, Ken Saro-Wiwa Polytechnic Bori, Rivers State, Nigeria
}

\begin{abstract}
This paper presents the design and implementation of SMS-based robotic system for hole-detection in surface pipes using GPS/GPRS/GSM technology. In industries today, surface pipelines are used to transport fluids; some of these pipelines have joints which are welded together. In a situation whereby the welding is not perfectly done, leakage of fluids may occur, leading to product loss and downtime. Therefore to checkmate this issue of pipeline leakage, an SMS-based robotic system is designed to inspect the pipelines for holes and if light is sensed in the pipelines through the sensing devices on the robot, a Short Message Service (SMS) indicating the location where the light was sensed is sent to the operator's phone with help of the SIM 900 GPS/GPRS/GSM MODEM installed on the robot hardware system. The robot system is designed with an Arduino Uno MicroController and some sensing devices installed on it. The system is programmed using embedded $C$ language. After the implementation, the robot system was tested which could detect holes in surface pipelines and sent short message to the personnel's mobile phone.
\end{abstract}

Keywords: Arduino Uno Board, GPS/GPRS/GSM technology, Robotics, SIM900 Modem, Sensors

\section{INTRODUCTION}

Robotics is one of the fastest growing Engineering fields of study today. Robots are designed to remove the human factor from labor intensive or dangerous work and also to act in inaccessible environment. The uses of robots are more common today than ever before and it is no longer exclusively used by the heavy production industries. There are many areas where robots can be used to replace humans; among them are monitoring of oil pipelines for leakages which are one of the most challenging areas in Oil \& Gas sectors. Over billions of places, from huge plants to an individual houses, robots are employed by people to carry out vast services. But, many troubles like aging, corrosion, erosion, cracks and physical damages from third parties, have occurred in pipelines. Therefore, maintenance of pipelines is essential in order to keep them functional, and moreover the continuation cost for these activities are being increased.

Autonomous robots can act on their own, independent of any controller. Autonomous pipe inspection method should be introduced for holes detection in surface pipes in order to improve the inspection efficiency by reducing the time and manpower in the inspection process. The in-pipe detection of holes in surface pipes is relevant for improving security and efficiency in industrial plants. These specific operations such as inspection, maintenance, cleaning etc. are expensive.
The application of the robots in pipeline inspection and monitoring appear to be one of the most attractive solutions. Due to the cost of advanced pipeline inspection techniques, less expensive forms of non-destructive evaluation are often desired. Visual inspection of surface pipes is currently one of the most commonly used non-destructive evaluation techniques because it is relatively inexpensive as it requires minimal, if any, use of instruments or equipment and it can be accomplished without data processing. However, a large number of structural deficiencies have surface indicators (e.g. Corrosion, concrete deterioration etc.). Aside from a limited range of detection, visual inspection does have further drawbacks. It is extremely dependent on the inspector's training, visual acuity, and state-of-mind. Also external factors such as light intensity, structure complexity, and structure accessibility play a role in determining the effectiveness of visual inspection.

\section{LITERATURE REVIEW}

The first reference to the word 'robot' appeared in a play opening in London. The play, written by Czechoslorakian Karl Capek introduced the word 'robot' from the Czech 'robota' (Webster, 1993) and (Karl, 1921).

The first programmable robot was designed by George Devol, and named it Universal Automation. He later shortened this to unimation which became the name of the first robot company (George, 1954). Richard Hohn 
developed the first commercially available minicomputercontrolled industrial robot for Cincinnati Milacron Corporation and is called the T3, The Tomorrow Tool (Richard, 1973). Microprocessors Group project students of Coventry University designed a robot vehicle using a PIC 18F4520 microcontroller board, stepper motors, Darlington Driver, photo reflective optical sensor, light dependent resistors and two switches,(Divay,2012). Jacob and Tyler developed a robot devoid of computer programming but follow the strongest light with obstacle avoidance sensors (Jacob, 2012). Nagaraju developed a light following Robot under the Guidance of NigeswarRao and M. Techn. He further explained that the robot, named 'visible light' is a robot that can sense and follow light source. A user can shine light at its front and light Rover will respond following the light source. The light Rover uses a microcontroller for processing the sensor readings and responds by controlling the motors (Nagaraju, 2014).

The visible light was designed with two sensor, one on the left and the other on the right such that when more light is detected on the left, the robot moved towards it by rotating the right motor forward and the left motor backwards. The robot also moved forward when both senses received the same amount of light .The robot has two bipolar motors attached to front wheels and the rear wheels do not have any motor attached to them. The robot has two sensors fixed at its front panel separated within a distance. It has a power supply and microcontroller placed inside the light Rover. Nagaraju's drive in building a sensing light robot was to explore microcontroller which are natural devices for sensing and responding to events.

Furthermore, in Ben's light following robot design, the motors were connected to the robots wheels which allow it to drive around. However if both light sensors detect the same amount of light, the wheels spin at the same speed so that the robot goes straight. If one light sensor detects more light than the other, one wheel will spin faster, which will make the robot turn (Ben, 2014).

\section{DESIGN METHODOLOGY}

The system design methodology used consists of hardware and software top-down approach. The hardware implementation approach of the system is shown in fig.3.1 which consists of the sensors, power supply, microcontroller, drivers, roller, GSM and display. The software approach consists of sequence of codes written in embedded C language for controlling the entire system. Each of the mentioned modules has its function to play in the system to ensuring efficient detection of any holes on the surface of the pipelines.

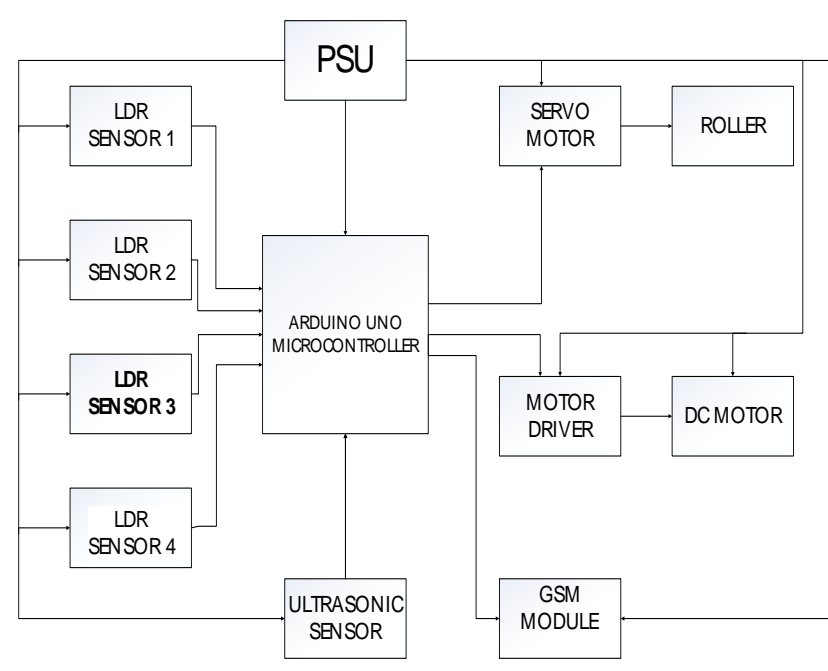

Fig 3.1: System hardware implementation block diagram

\subsection{Power Supply}

The system requires $+5 \mathrm{~V}$ DC power supply for its operation. One possible source of the $5 \mathrm{~V} \mathrm{DC}$ is the use of one or more 9V DC batteries connected in series. In this work, two $9 \mathrm{~V}$ DC batteries connected in series are used as a power source to the robot system. The $18 \mathrm{~V}$ voltage shown in figure 3.2 is regulated using 7805 voltage regulator to ensuring constant 5V D.C voltage for powering special unit of the system, like the ArduinoUuno microcontroller and sensor units.

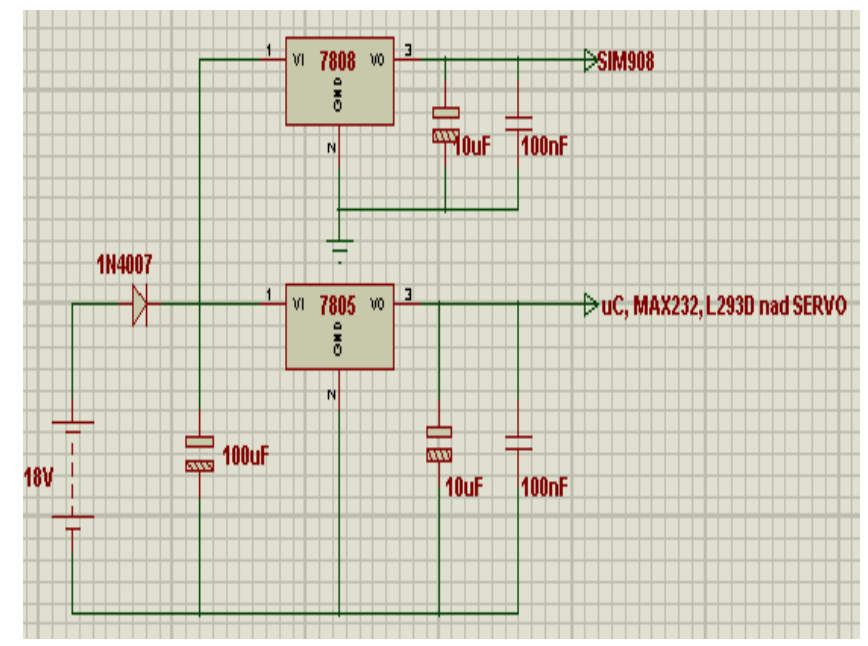

Fig.3.2: $+5 \mathrm{~V}$ regulated system power supply

\subsection{Ultrasonic Sensor}

The ultrasonic sensor interface with the Arduino Uno board is shown in figure 3.3 which has four connection pins namely VCC, TRIGGER, ECHO AND GND. The VCC and the GND when connected properly provide power to the system units. The trigger and the echo are for calculating the distance of the object away from the module. A high (logic 1) to the trigger pin forces the sensor to emit ultrasonic sound from the sound emitter of the module which travels through the air to the object and reflect back to be received by the module receiver. Thus, the distance covered by the sound for the complete journey tells how far or near the object is from the robot. 


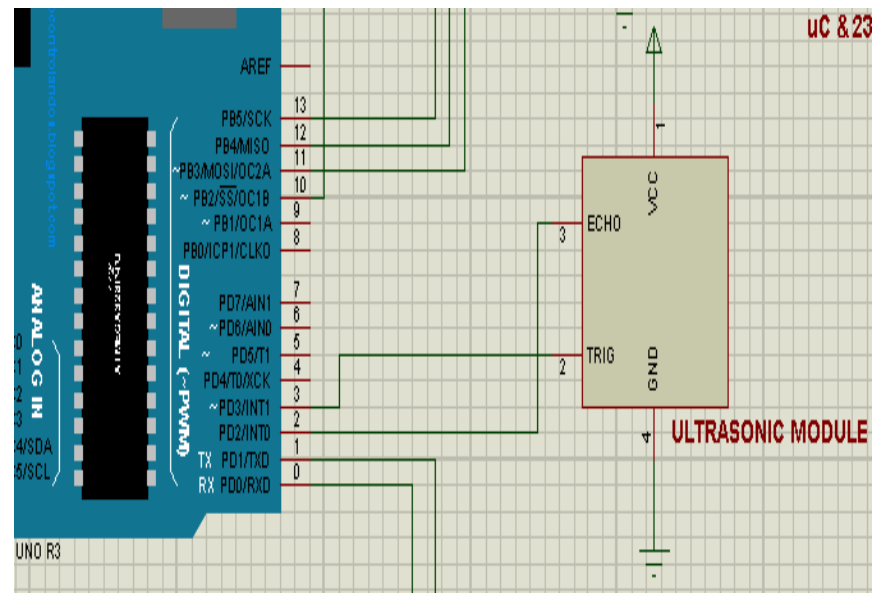

Fig.3.3: Ultrasonic module Interfaced with Arduino

\subsection{GSM Modem}

The GSM modem is connected to communicate with the Arduino microcontroller via Max-232 level converter as shown in figure 3.4. The AT commands are used to link the communication to SIM900 GSM/GPRS modem. The $\max 232$ is used to convert the voltage signal level of Arduino controller to be compatible with the GSM Modem voltage level. The Transmit (TX) pin of the modem is connected to the RS-232 input pin (R1IN) of the max232 and the T1OUT of $\max 232$ to receive $(\mathrm{RX})$ pin of the Arduino. The receive (RX) pin of the modem is also connected to the RS-232 output pin of the max232 and the T1IN to the Transmit (TX) pin of the microcontroller. With this connection the modem and the controller can exchange data successfully.

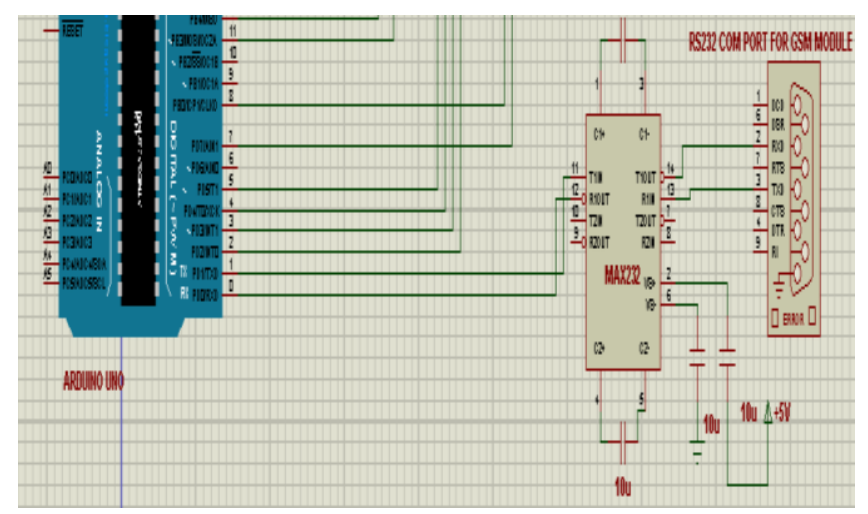

Fig.3.4: Arduino Controller interface with the GSM modem

\subsection{Microcontroller Unit}

The Control unit coordinates and controls all the signal flow in respect to what it receives from the input units, and ensures necessary action is taken. The Arduino Uno micro controller is selected to coordinate all transmit and receive signals within the system due to some of it properties such as, flexibility, the RAM size, number of programmable I/O lines, programmable serial channel, etc. The control unit circuit board is shown in figure 3.5.

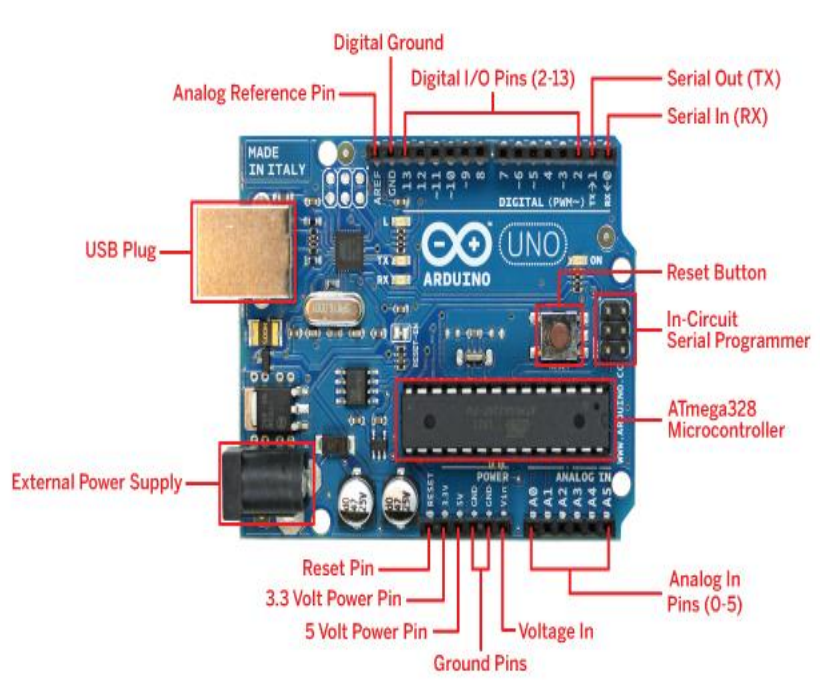

Fig.3.5: System control unit

The control unit makes use of Arduino-uno microcontroller chip, which main function is to control locomotion, direction, detect holes in pipes and send the co-ordinate point location at which the holes occurred through SMS to a remote monitor. All individual input sensors (LDR) and locomotion actuators (servo and DC motor) were connected in the I/O pins of the microcontroller as shown fig 3.8 in the complete system diagram below. The Arduino-uno is the heart of the entire system where input and output information are processed and the necessary action taken.

\subsection{Motor \& L293D motor Driver}

One DC motor is used on this robot to initiate and aid locomotion very effectively. It propels the rear wheels of the robot into motion on a given command from the microcontroller. Below are the specifications of the DC motor used:

- Motor rated voltage: 3-5VDC

- Max motor voltage : 6VDC

- No load speed : $90 \pm 10 \mathrm{rpm}$

- No load current: 190mA (max. 250mA)

- Torque: 800 gf.cm

- Motor stall current: $170 \mathrm{~mA}$

However, the microcontroller can only produce a maximum current of $100 \mathrm{~mA}$. With that, the L293D is a standard 16-pin dual-in line package (DIP) motor driver IC that can simultaneously control two small motors in either direction; forward and reverse with just four microcontroller pins. This integrated circuit can drive the DC motor, relay solenoids, stepper motors etc. in this work, the IC driver is used to drive a single DC motor connected at the back of the robot to control and create locomotion. The figure 3.6 shows the interfacing of the motor to Arduino microcontroller. 


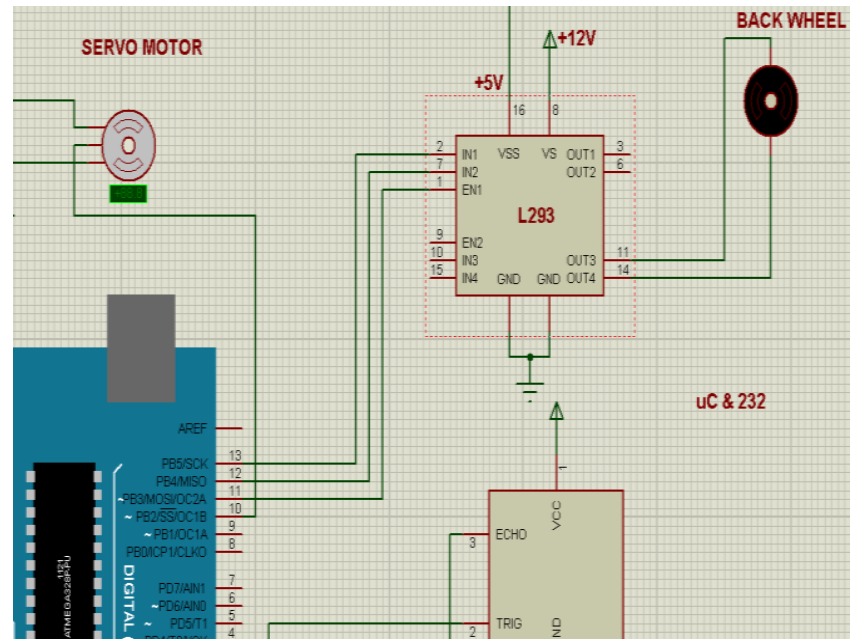

Fig.3.6: DC \& Servo Motors interface with Arduino Controller

\subsection{System Simulation Software \& Code Language}

The simulation design software used for this research work is Proteus 8.1 professional and the program source code developed and compiled in Arduino Integrated development environment using embedded $\mathrm{C}$ language. The flow chart used to actualize the research objectives is shown in figure 3.7 .

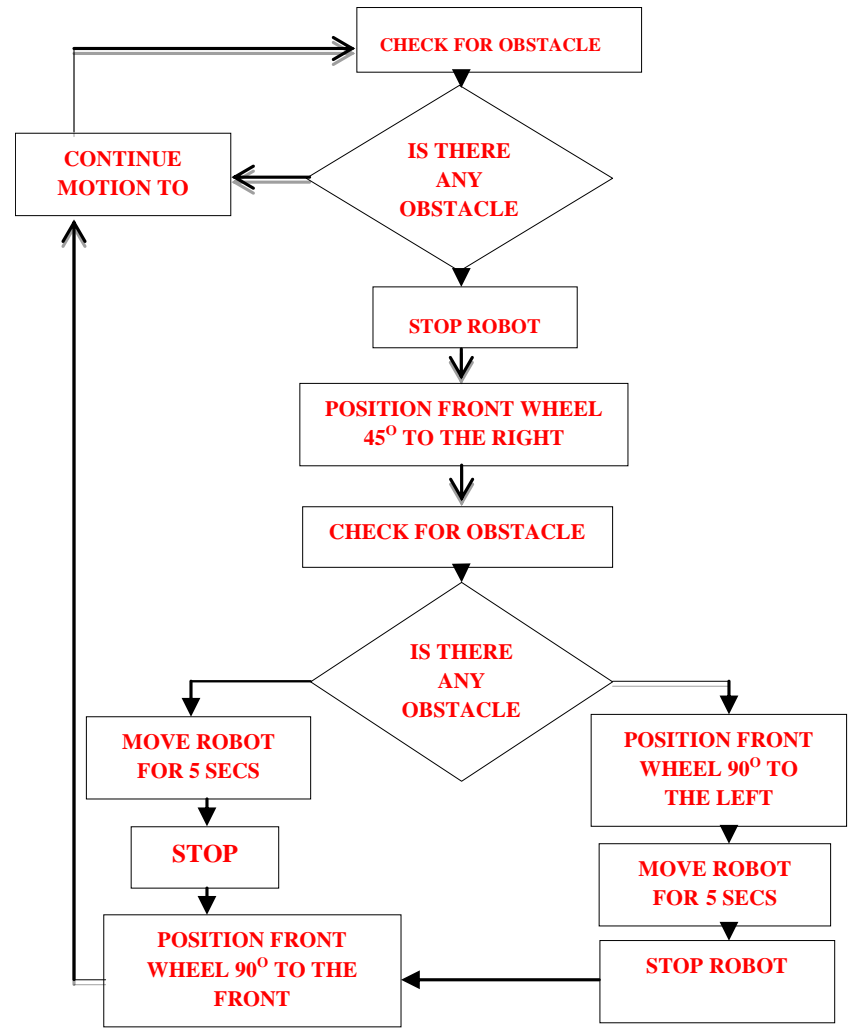

Fig. 3.7: System program design flow chart

\subsection{System Operation \& Circuit Diagram}

The system is designed to inspect and check oil pipelines and send SMS to the pipeline operators and maintenance team when hole is detected before oil is allowed to flow in the pipelines. The robot system assists in tracing any hole in the pipe and relates the location appropriately to the operator through GSM modem. When there is a new pipeline to be checked, the robot system is energized and sent to the beginning of the pipe. The two sensors (ultrasonic and LDR) begin to sense holes in a pipe as it moves towards the end of the pipe. The DC and servo motors propel the robot in the forward direction as it moves in the pipe. When hole is detected, the robot sends a short message to the operator indicating the coordinate and location of the holes. The system designed circuit diagram is shown in figure 3.8

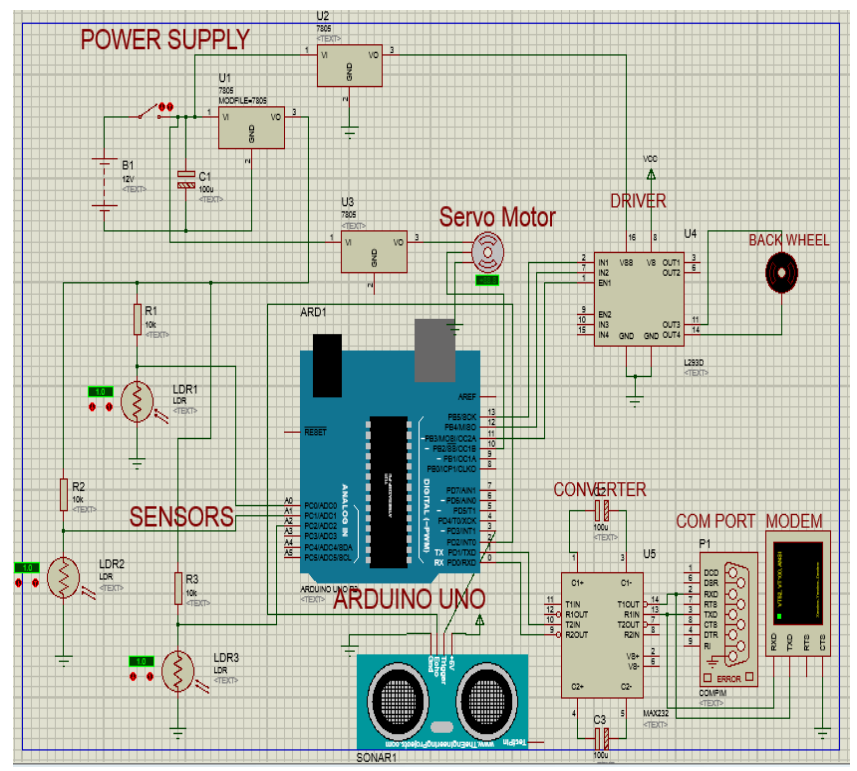

Fig.3.8: System Circuit Diagram

\section{RESULT \& DISCUSSION}

After hardware design and interfacing, the program source code is written, complied and burned into the Arduino microcontroller. Each of the hardware components of the vehicle is subjected to functionality test and their reliability ascertained before they are assembled. The final assembled product is shown in figure 3.9.

\subsection{System Test \& Results}

\section{- Microcontroller Test}

The System board is switched on and Arduino Uno microcontroller input powered output measured to be $5 \mathrm{~V}$ using a digital meter at different interval of time to ensure steady voltage. Also continuity test was carried out on each of its pins to ensure that the controller is in good condition. Before final integration of different system units, the following were tested and results satisfied:

\section{- Motor Driver Test}

Continuity test is carried on the motor driver IC chip pins, it was powered from the circuit power supply and the expected $5 \mathrm{~V}$ signal was seen.

\section{- DC Motor Test}

The coil of each of the DC motor is tested and the resistance found to be $5.4 \Omega$ while that of the body of the coil was infinity.

- Light Dependent Resistor (LDR) Test

Each of the three LDRs is tested for functionality and their resistance was found to be $10 \mathrm{k} \Omega$. 


\section{- Servo Motor Test}

The servo unit is tested by connecting to a DC supply, and a pulse width signal supplied for rotation check.

\section{- The SIM 908 GSM Modem Test}

The modem is powered from the Arduino $+5 \mathrm{~V}$ regulator supply via microcontroller. A delay of 5 seconds is required to get it ready for communication. There are two jumpers responsible for setting the modem in GPS and SMS mode. These were set at the appropriate places to suit design need. Continuity was carried out to ensure the TX pin of the modem is connected to the RX of the Arduino and the RX pin of the modem to the Arduino TX pin. This connection test was ascertained to be correct.

After integration of the sub-units of the system, the complete system picture is as shown in fig. 3.9

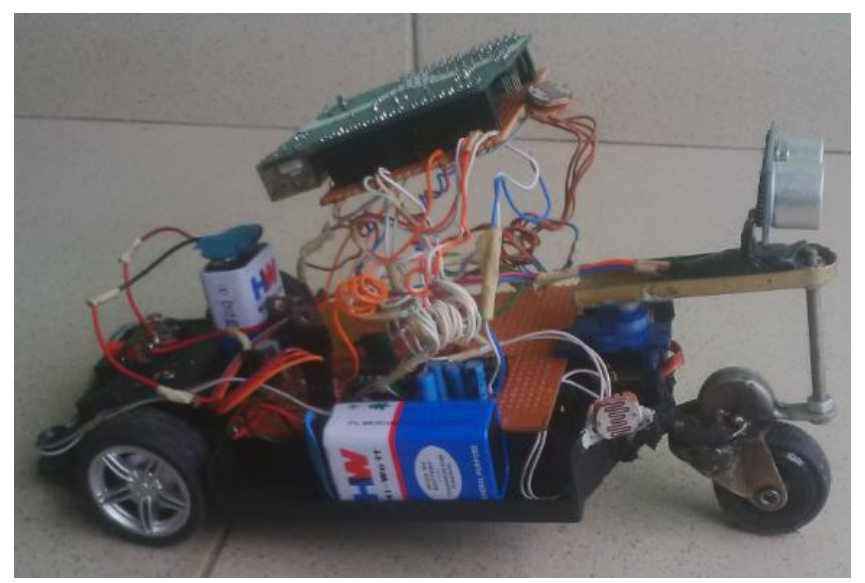

Fig 3.9: Assembled system hardware

\section{CONCLUSIONS}

The fault detecting robot in a surface pipeline has been designed and tested, and confirmed to be functional as shown in fig 3.9 above. The robot is an innovative and autonomous design that is active in detecting holes in surface pipelines. The device can be used to monitor and inspect surface pipeline areas for fluid transport taking note of pipe dimension with regard to the robot size. It will promote prevention of product wastage such as crude oil, water during transportation if adopted etc.

\section{ACKNOWLEDGEMENT}

We would like to express our deepest appreciation to God for making this paper a success. Special thanks to our families for all their moral and financial support throughout the research work. Also, to IJRET editors for having prepared this wonderful template, their commitment and prompt response in attending to journal papers

\section{REFERENCES}

[1]. Anjumanara, B.(2014), "Line following robot without using micro-controller". International Journal on Research and Innovation Trends in Computing and Communication: |Vol 2; Issue 2|. Available at www.slideshare.net (Accessed 2015-10-07)
[2]. Anurag, Y. (2014). "Light follower bot". Available at www.slideshare.net/aurahyadav94/light-follower-robot (Accessed 2015-10-03)

[3]. Ben,F.(2014). "Bluebot Project". Available at www.sciencebuddies.org/science-fairprojects/Robotics(Accessed 2015-10-03)

[4]. Divay,K.(2012). "Light sensing robot". Available at www.slideshare.net (Accessed2015-10-03)

[5]. George, D.(1954), "History of Robots in Research". Available at www.robots.com (Accessed 2015-10-05)

[6]. Jacob, D \& Taylor, S (2012), "Light following Robot”. Available at www.inside.mines.edu (Accessed 201510-05)

[7]. Karl, C (1921), "History of Robots in Research". Available from www.robots.com (Accessed 2015-1005)

[8]. Nagarajum, M.(2014),"Visible Light follower Robot". Available atwww.docslide.us/engineering/visible-lightfollower-robot by nagarajum by nagaraju.html (Accessed 2015-10-05)

[9]. Richard, H. (1973), "History of Robots in Research". Available at www.robots.com(Accessed 2015-10-05)

\section{BIOGRAPHIES}

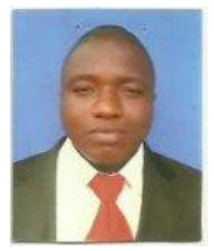

Ezeofor Chukwunazo Joseph received his B.Eng. in Computer Engineering at Enugu State University of Science and Technology (ESUT) and M.Eng in Communication Engineering at Federal University of Technology Owerri (FUTO). Ezeofor is currently studying Ph.D in Computer and Control Systems Engineering at Nnamdi Azikiwe University (NAU) Awka Nigeria. He has done over five publications and supervised more than fifteen students. He is a member Nigerian Society of Engineering (NSE) and registered member of Council of Regulation of Engineering in Nigeria (COREN). His research interest is on Real Time Embedded Systems, Control Systems, and Telecommunication. He is happily married with children.

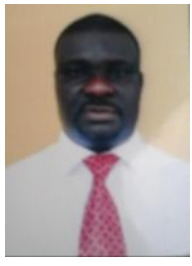

Georgewill Onengiye Moses got his B.Sc. in Computer Science at University of Nigeria Nsukka and first M.Sc in Applied Geophysics at Rivers State University of Science \& Technology Port Harcourt (RSUST).He also received his second (M.Eng) in Federal University of Technology Owerri (FUTO). Georgewill further had third master's degree M.Sc in Computer Science at University of Port Harcourt (UNIPORT) and finally Ph.D in Computer Science in the same Institution. He is currently the Rector, Ken Saro Wiwa Polytechnic Rivers State, Nigeria. Georgewill has done over thirty publications. He is a member of Nigeria Computer Society (NCS), Association of Computer Machinery (ACM), Institute of Electrical and Electronic Engineering (IEEE), Computer Professionals (Registered Council) of Nigeria (CPN), International Research and Development Institute (IRDI). His research interest is in Artificial Intelligent (Fuzzy logic, Neural Network etc), Robotics, Computer Vision etc. He is happily married with children. 